Development and In-Flight Performance of the Mziviner 9 Spacecraft Propulsion System

\author{
D. D. Evans
}

R. D. Cannova

M. J. Cork

(NASA-CB-129997) DEVELOPMENT AND IN-ZLIGHT

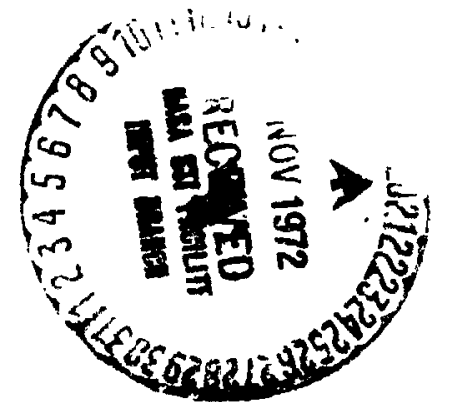


NATIONAL AERONAUTICS AND SPACE ADMINISTRATION

Technical Memorandum 33-574

\title{
Development and In-Flight Performance of the Mariner 9 Spacecraft Propulsion System
}

D. D. Evans

R. D. Cannova

M. J. Cork

\author{
JET PROPULSION LABORATORY \\ CALIFORNIA INSTITUTE OF TECHNOLOGY \\ PASA DENA, CALIFORNIA
}

November 1, 1972 
PRLCEDING PAGE BLANK NU1 rishid)

\section{PREFACE}

The work described in this report was performed by the Propulsion Division of the Jet Propulsion Laboratory. 


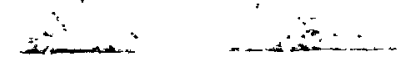

\section{PRLILDING PAGE BLANK NOT H ILMLAS \\ CONTENTS}

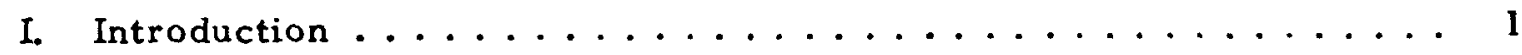

II. Description and Operation .................. 2

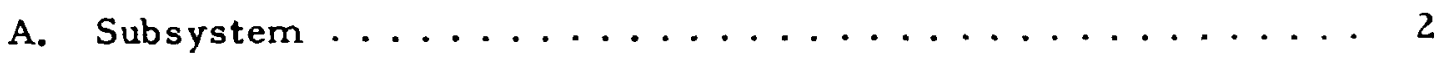

B. Propellant Feed System ................... 4

C. Rocket Engine Assembly................... 5

III. Subsystem Derelopment ...................

IV. Flight Acceptance and Qualification Testing .......... 7

A. Proof and Leak Test .................. 7

B. Functional Tests .................... 8

C. Vacuum Chamber Leak Test ................ 8

D. Qualification (Type Approval) Test Program ......... 8

v. Launch Preparation ....................... 10

VI. Mission Sequence ................... 11

VII. Analytical Modeling anc Flight Performance Correlations ..... . 12

A. Nitrogen Solubility Effects and Mass Transport Model ...... 12

B. Operation and Performance Computer Program . . . . . . . . 14

C. Flight Analysis Computer Program ............. 15

D. Performance Results .................... 16

vill Conclusions ....................... 16

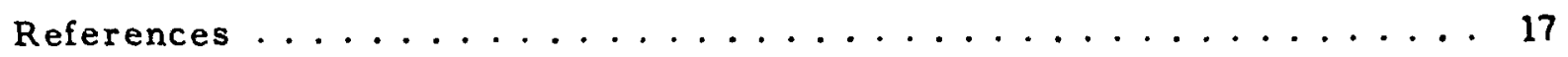

\section{TABLES}

1. Propulsion subsystem performance characteristics ....... 18

2. Mariner Mars 1971 propulsion weight summary

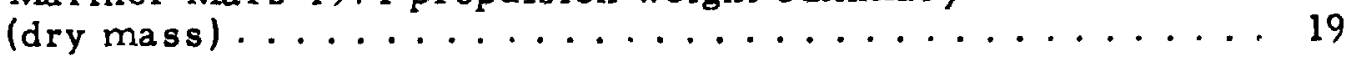

3. Type approval test series $1 \ldots \ldots \ldots \ldots$

4. Type approval test series $2 \ldots \ldots \ldots \ldots \ldots$ 
CONTENTS (contd)

\section{TABLES (contd)}

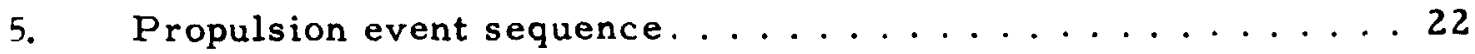

6. Orbit insertion propulsion performance summary ....... 23

7. Mariner 9 propulsion maneuver summary .......... 24

\section{FIGURES}

i. Mariner M rs 1971 spacecraft ............. 25

2. Schematic iiagram of Mariner Mars 1971 propulsion

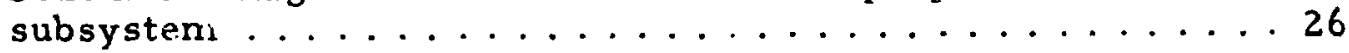

3. Mariner 9 propulsion subsystem ............ 27

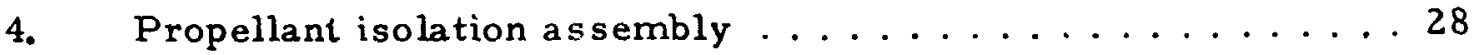

5. Mariner Mars 1971 rucket engine assembly . . . . . . . 29

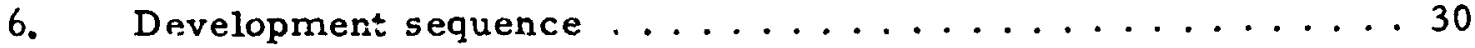

7. Propellant tank gas diffusior model .................. 31

8. Propellant tank pressures compared with saturation

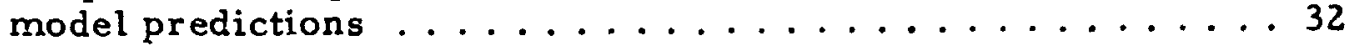

9. Subsystem performance prediction program .......... 33

10. Propulsion model of PSOP block diagrarn ........... 34

11. Thrust chamber pressure during orhit insertion ....... 25 
On November 14, 1971, Mariner 9 was decelerated into orbit about Mars by a 1334 -newton (300-lbf) liquid bipropellant propulsion system. This paper describes and summarizes the development and in-flight performance of this pressure-fed, nitrogen tetroxide/monomethyl hydrazine bipropellant system. The design of all Mariner propulsion subsystems has been predicated upon the premise that simplicity of approach, coupled with thorough qualification and margin-limits testing, is the key to cost-effective reliability. The Mariner 9 subsystem design illustrates this approach in that little functional redundancy is employed. This paper summarizes the design and test rationale employed in the Mariner 9 design and development program.

The qualification test program and analytical modeling a re also unscussed. Since the propulsion subsystem is modular in nature, it was completely checked, serviced, and tested independent of the spacecraft. Proper prediction of in-flight performance required the development of three significant modeling tools to predict and account for nitrogen saturation of the propellant during the six-month coast period and to predict and statistically analyze in-flight data. The flight performance of the subsystem was excellent, as were the performance prediction correlations. These correlations are presented. 


\section{INTRODUCTION}

The Mariner 9 Mars-orbiter spacecraft was the sixth in a series of Mariner spacecraft which have explored the planets Mars and Venus since 1962. The previous five spacecraft completed flyby missions which piovided only brief encounters with the target planet. The Mariner 9 spacecraft, however, was placed in a 12-hour orbit about Mars, thereby allowing a repeat of the close encounter sequence twice a day for an extended period of time. Scientific instruments included a wide-angle television camera for surface mapping, a narrow-angle television camera for close-up studies, two infrared instruments, and one ultraviolet instrument for surface and atmospheric properties measurements. Behavior of the spacecraft radio signal at the entrance and exit of Earth occultation phases provided additional atmospheric information, and the orbital characteristics allowed study of the Mars gravitational field.

The earlier Mars and Venus spacecraft utilized small monopropellant hydrazine spacecraft propulsion systems designed to accomplish up to two interplanetary trajectory correction maneuvers. The Mariner 9 spacecraft, illustrated in Fig. 1, was designed to use the basic Marine 6 and 7 (Mariner 1969) spacecraft with the incorporation of a new and larger propulsion subsystem. This bipropellant subsystem was designed to accomplish in-transit trajectory corrections, to decelerate the spacecraft from a hyperbolic approach trajectory into an elliptical orbit about Mars, and to perform subsequent orbit trim maneuvers as required.

The basic Mariner propulsion philosophy embodies three key principles:

(1) Provide cost and weight effectiveness by simplicity of design coupled with thorough margin limit testing. For unmanned spacecraft, this approach, rather than that of redundancy, has proven successful. 
(2) Design the propulsion subsystem to be modular and man-rated when fueled and pressurized. This approach allows subsystem fabrication and propulsion testing independent of the spacecraft, thus decoupling expensive spacecraft operations from propulsion operations. This proves to be extremely valuable during launch preparations where the tested, fueled, and pressurized propulsion system can be independently checked ard fueled and later delivered to the spacecraft for mating and encapsulation.

Provide "pathfinders" for all critical operations. Prior to assembly, test, or other operations on flight hardware, "pathfinder" operations are conducted wherein all personnel, procedures, and equipment undergo a dress rehearsal before hazarding the flight hardware.

These principles were applied to the Mariner 9 design and development as will be discussed subsequently.

\section{DESCRIPTION AND OPERATION}

\section{A. Subsystem}

The propulsion subsystem is shown in Figs. 2 and 3. The subsystem pressurization is by gaseous nitrogen. Pressurant is isolated from the remainder of the subsystem by the commandable pyrotechnic valves of the pressurant control assembly (PCA). Upon actuation of one of the PCA normally closed valves, pressurant flows from the pressurant tanks through the pressurant filter and the regulacor, whose outlet pressure is controlled to $1741 \times 10^{3} \mathrm{~N} / \mathrm{m}^{2}\left(253 \mathrm{lbf} / \mathrm{in.}^{2}\right)$. After flowing through the regulator, pressurant flows into the pressurant check and relief assembly (PCRA) and into the propellant tanks.

Once in the propellant tank, the pressurant causes the bladder to collapse about the standpipe and expel propellant through the gas separation device and into the propellant isolation as sembly (PIA). The PIA controls propellant flow to the rocket engine with three normally closed and two normally open pyrotechnic valves and a filter. After leaving the PIA, propellant flows through the flex lines, which permit gimballing of the 
rocket engine, and to the rocket engine solenoid valve. The rocket engine operates with $\mathrm{N}_{2} \mathrm{O}_{4}$ and $\mathrm{MMH}$ at a mixture ratio of $1.57: 1$; the hot gases are expelled through a nozzle with an expansion ratio of 40:1.

Servicing valves ape used to provide access to the inlet and outlet sides of the pyrotechnic valves in the PCA and PIAs, to the downstream side of the check valves in the PCRA, and to the propellant tank side of each standpipe. Pressure transducers provide pressure information at the PCA inlet, downstream of the check valve in the PCRA, and at the PIA outlet as well as providing rocket engine combustion chamber pressure.

The propulsion support structure, a beryllium tube truss with magnesium and steel fittings, is attached to the upper octagonal spacecraft frame and supports the propulsion equipment, the high-gain antenna, and the lowgain antenna.

The following operating sequence was that upon which the subsystem design was based. A later section describes the sequence actually followed. Before the first trajectory correction, the engine valve must be opened to bleed the air trapped between the normally closed propellant pyrotechnic valves and the engine valve. Actuation of the first set of pyrotechnic valves, P-1, O-1, F-1, pressurizes the propellant tanks and allows propellant flow down to the engine valve. The trajectory-correction maneuver is performed by opening the engine valve; this causes the propellant to flow into the thrust chamber, undergo hypergolic ignition, and continue to burn until such time as the desired velocity increment is nbtained as determined by an on-board integrating accelerometer. At this time, the engine valve is closed by removing its electrical power. Later, the propellant and pressurant lines are closed by actuation of the second set of pyrotechnic valves, P-2, O-2, F-2, to guard against leakage after tracking data confirm that no more propulsion maneuvers will be required before the nominal time of the second trajectory correction. The pressurant and propellant lines are reopened, by the third set of valves, $P-3,0-3, F-3$, just before the second trajectory correction, if such a correction is needed. The valves remain open for the orbit insertion maneuver. The orbit insertion maneuver was expected to involve an approximate $840-\mathrm{s}$-duration burn to place the spacecraft into the initial orbit. Within two days after orbit insertion, one or two orbit trim maneuvers 
were anticipated to place the spacecraft in a precision 12 -hour period orbit. After tracking data confirm correct orbital characteristics, operation of the fourth set of valves, P-4, O-4, F-4, is possible to isolate the propulsion fluids for the rest of the mission. An additional set of valves, P-5, O-5, $F-5$, is available for subsequent maneuvers if needed.

Actuation of the pyrovalves and management of solenoid powe $r$ for the engine valve is accomplished by necessary power switching in the pyrotechnics subsystem. Thrust vector control during engine firing is provided by the use of gimbal actuators for pitch and yaw control and cold gas jets for roll control.

Referring again to Fig. 2, note how the components are arranged into identifiable subassemblies. Each subassembly contains a group of components that can be physically located together and fu.ctionally tested as a subassembly. Also note the commonality of the subassemblies. The pyro valve assembly, common to three of these, was designed to be interchangeable, thus allowing a "production" run of this building block. Furthermore, the fuel and oxidizer piessurant check and relief assemblies are identical, allowing economies in design, production, test, and spares provisioning. This also is the case with the fuel tank assemblies and the propellant is olation assemblies.

Table 1 summarizes the propulsion subsystem performance characteristics; Table 2 is a weight summary.

\section{B. Propellant Feed System}

The fabrication of the propellant feed system major subassemblies was performed by the Martin Marietta Corp. (MMC), Denver Division, under contract to JPL. This responsibility included the procurement of the components and their acceptance and qualification testing. The only components not purchased by MMC were the propellant tank shells and the flex lines, which were procured by JPL. The components were incorporated with detail parts machined by MMC to form the subassemblies, which were then acceptance tested and provided to JPL. Figure 4 shows a completed subas sembly. 
Upon their receipt at JPL, the subassemblies were mounted on the subsystem structure and joined to their interconnecting plumbing. When assembly of the propulsion subsystem was completed, it was then subjected to the subsystem flight acceptance test.

The connection of components within subassemblies and the interconnection of subassemblies within the propulsion subsystem was accomplished by in-place induction brazing. With this technique the number of mechanical exteinal seals on the subsystem was reduced to 16: 10 service valves, each with a primary and a redundant seal, two tank flanges with aluminum crush gasket seals, and four "AN-type" fittings, two on each flex hose, with crushable aluminum seals. This fabrication technique resulted in a subsystem external leakage rate of less than $1 \times 10^{-5} \mathrm{STP} \mathrm{cm}^{3} / \mathrm{s}$ when the subsystem was pressurized to its operating pressures with helium.

Components from existing programs were selected wherever possible to minimize development and qualification. Some minor changes and improvements were incorporated in several components due to performance requirements and the need fo- long-term exposure to propellants.

After manufacture, the subassemblies were flight-acceptance-tested before being integrated into the subsystem. The sequence of FA testing was to ensure proper assembly, functional operation, and cleanliness verification.

\section{Rocket Engine Assembly}

The Mariner 9 rocket engine, shown in Fig. 5, was manufactured b: the Rocketdyne Division of North American Rockwell Corporation. It is a two-piece conductively cooled combustion chamber and radiation-cooled nozzle extension. The engine is equipped with a torque-motor-operated, mechanically linked bipropellant control valve produced by the Moog Corporation, Aerospace Division, East Aurora, New York. The combustion chamber, fabricated from hot-pressed beryllium, is attached to the 40:1 cobalt alloy nozzle extension by a Renè-4l nut. The engine employs a unique method of thermal control developed by its manufacturer, and termed "INTEREGEN." Heat transfer red convectively to the engine is conducted through the thick, highly concictive chamber walls and 
transferred, again convectively, to the boundary layer coolant (BLC) covering the thrust chamber walls near the injector. The BLC covering is also convectively heated from the hot gas side. In this manner the engine can run for long periods with a near-steady temperature distribution. Success of this cooling technique depends on the heat absorption capabilities of the BLC and the proper thermal management in the metal walls so that adequate protection irom the hot combustion gases is afforded.

\section{SUBSYSTEM DEVELOPMENT}

The subsystem development sequence is shown in Fig. 6. Early design of the subsystem made maximum use of previously qualified hardware. The conceptual design was first evaluated in the breadboard system using surplus or prototype hardware. Tests vere conducted using this system to evaluate general operation and characteristics.

The engineering test model (ETM) was the initial subsys $m$ with fully operational components and subassemblies. The ETM was user to evaluate operation and performance of the subsystem over a wide range of contitions and environments. It also served as a pathfinder for fabrication, assembly, checkout, and other operational aspects.

The ETM was loaded with solvents and subjected to flight-acceptance and type-approval vibration in a single axis. Five hot firing test stries were conducted on the ETM in order to pathfind the conditions planned for thic type approval (qualification) program and to evaluate pertormance after longterm (three-month) exposure to propellart. The results indicatec that the ETM operated and performed satisfactorily.

Early in the design phase of the propulsion subsystem, the comparisons and tradeoffs between welding and brazing of tube-to-tube and tube-tocomponent joints were resolved to a choice of the induction brazing process.

Ae roquip equipment (Ae roquip Corp., Aircraft Division, Jackson, Michigan) was utilized, consisting of (1) a $15-\mathrm{kV}$ water-cooled induction generator/voitage regulator combination, (2) a remoie console, whic a was connected via $R F$ cable, wat $\in \mathrm{r}$ cooling, and argon gas lines to the induction generator, and (3) the water-cooled braze tools. During the course of the 
braze development and early stages of the assembly buildup, special considerations relative to cleanliness and preparation of material and techniques for maintaining inert envircnments in the braze joint zone were found necessary to consistently accomplish good brazes.

\section{FLIGHT ACCEPTANCE AND QUALIFICATION TESTING}

At the completion of fabrication, each flight propulsion subsystem was subjected to the following test sequences:

(1) Proof and leak.

(2) Functiona1.

(3) Vibration.

(4) Vacuum chamber leakage.

(5) Postvibration fuctional.

In addition, the flight subsystems underwent the rmal vacuum and vibration tesing while instailed on the spacecraft. Isopropyl alcohol and Freon were used as fuel and oxidizer simulants during vibration tests.

\section{A. Proof and Leak Test}

A proof press -e test was performed to demonstrate integrity of the subsystem at pressure levels of 1.5 times the normal working pressure for various components of the subsyster.2. The levels of pressure for parts of the subsystem varied from $41.4 \times 10^{6} \mathrm{~N} / \mathrm{m}^{2}\left(6000 \mathrm{lbf} / \mathrm{in} .^{2}\right)$ for the pressurant bottles to $172 \times 10^{6} \mathrm{~N} / \mathrm{m}^{2}\left(250 \mathrm{lbf} / \mathrm{in} .^{2}\right)$ for the rocket engine.

The purpose of the leak test was to verify trat zero leakage was obtained at the many braze joints of the subsystem which had been added to interconnect subassemblies, Helium gas was used as the leak detection medium, with a portable helium mass spectrometer as ihe detector. In addition to the braze joints, various other areas of the propulsion sul system such as the servive valves and the rocket engine assembly flex hoses were leak-checked at working pressure. 


\section{B. Functional Tests}

The propulsion subsystem functional test had three objectives:

(1) To verify that all subassembly componerts meet their flight performance criteria.

(2) To observe any possible adverse interaction between components when they are operating under normal conditions.

(3) To provide assurar. that the functional operation of a component has not been compromised as a resuit of other subsystem tests such as ribration.

The key functional tests were:

(1) Regulator lockup test.

(2) Relief valve assembly functional test.

(3) Check valves cracking pressure and leak test.

(4) Rocket engine valve and flow tests.

(5) Gimbal actuator functional test.

\section{Vacuum Chamber Leak Test}

The purpose of the vacuum chamber tests was io verif; that the propulsion subsystem total external leakage was within specification when pressurized with helium at working pressure. A secondary purpose of the test was to verify that outgassing of various components on the subsystem, such as cabling, was within acceptable limits. Although the two propellant tanks were pressurized, no attempt was made to pressirize the feed lines to the REA since these lines normally contain only liquid propellant. Furthermore, helium gas would soon have permeated the Teflon lining of the flex hoses and obscured the test results.

\section{Qualification (Type Approval) Test Program}

The broad objectives of the type approval (TA) program were, as nearly as practicable, to simulate the processes, interfaces, tests, 
environments, and duty cycle that an actual flight subsystem would experience. In additior, it was intended to expose the subsystem to limits or environments, where appropriate, beyond expected conditions so as to demonstrate a level of margin. Most notably, the extended conditions were (1) higher level and increased duration for mechanical vit - ation, (2) operation at ext :eme temperature limits, (3) two mission duty cycles, (t) ext $\mathrm{r}$ a handling and servicing, (5) additional functional and component checks, and (0) other extended operating linits such as high tank pressures, extreme nonoperating temperatures, and extreme engine valve temperatures.

The TA subsystem was assembled, tested, handled, and, in general, exposed to conditions similar to those that flight units would experience. Following this, the TA subsystem underwent two simulated mission duty cycles. In the vibration testing, the TA was subjected to more severe conditions tinan expected on the flight units, ar. $d$ in the two mission duty cycles, the TA unit was exposed to specific extended environments.

The fact that the pyrotechnic valves were irreversible in operation precluded a complete simulation, so the sequences we re folded as shown in Tables 3 and 4 . The total engine firing time of each test series exceeded that expected for flight. Therefore, the engine, filters, bladders, and service values demonstrated margin in capacity and cycle capability.

The cngine was heated to $338.7 \mathrm{~K}\left(150^{\circ} \mathrm{F}\right)$ prior to the first midcourse firing, $¥$ pproximately $11 \mathrm{~K}\left(20^{\circ} \mathrm{F}\right)$ hotter than the temperature predicted from solar radiation; the subsystem was heated to $303.7 \mathrm{~K}\left(87^{\circ} \mathrm{F}\right)$, near the maximum of its specified range $\left(305.4 \mathrm{~K}, 90^{\circ} \mathrm{F}\right)$ and $6.7 \mathrm{~K}\left(12^{\circ} \mathrm{F}\right)$ hotter than the temperature predicted for the first midcourse maneuver. Cold propellants were then loaded for test series 2; the propellants were at $280.3 \mathrm{~K}\left(45^{\circ} \mathrm{F}\right)$ at the time of the orbit insertion firing, compared to an expicted temperature of $297 \mathrm{~K}\left(75^{\circ} \mathrm{F}\right)$. These temperature extrenes were intended to demonstrate margin for bladder collapsing, engine valve operation, check valve operation, and the operation of other temperature sensitive components. Saturated propellants were not used for testing, since analysis had shown that the predicted level of saturation at the time of orbit insertion would be well below the threshold required to affect per formance. The orbit insertion firing of test series 2 was performed with 
propellant tank pressures initially $17 \mathrm{~N} / \mathrm{cm}\left(25 \mathrm{lbf} / \mathrm{in} .{ }^{2}\right)$ higher than expected, simulating tank heating or regulator gas leakage.

Except for a check valve momentary sticking problem, which was later satisfactorily resolved, all components functioned as expecte 1 . All specification requirements were satisfied. Reliability of the propulsion subsystem was demonstrated and all interfacing equipment, such as pyrotechnics, thermal, structure, and support equipment, operated satisfactorily.

\section{LAUNCH PREPARATION}

The refurbished engineering test model was shipped to AFETR and used as a pathfinder for a complete exercise of the prelaunch operations to be performed on the flight subsystems. A typical sequence of testing was conducted which included helium leak test, functional test, squib installation propellant loading operations, propellant unloading, and vacuum drying of the subsystem. All the procedures and support equipment, as well as facilities to be used in flight operations, were successfully employed. As a result of performing the operations on the pathfinder subsystem and conducting the propellant loading operations, modifications we re made in the formal procedures for use during operations with the actual flight subsystems.

The pathfinder subsystem was later used with the PTM spacecraft for launch vehicle interface testing. All the testing was successful and provided an excellent proving ground before prelaunch preparations on the flight systems.

The preparations of the propulsion subsystems for launch at AFETR can be divided into three main areas:

(1) Performance of a subsystem leak test similar to the proof and leak test conducted at JPL but without taking the subsystem to the proof pressure levels.

(2) Repeat of the propulsion subsystem functional test.

(3) Installation of pyrotechnics, fuel and oxidizer fill, and pressurization of the subsystem. 
In addition to the two flight subsystems, the PTM subsystem was also fueled and pressurized and maintained in readiness as a spare. After preparation, the subsystem pressures were monitored prior to delivery to the spacecraft. In addition, a toxic vapor detector was used to detect any possible propellant leakage.

After installation onto the spacecraft, and prior to launch, pressure monitoring was accomplished through the spacecraft telemetry system when the spacecraft was undergoing electrical tests. Toxic vapor detector monitoring was also continued up through launch.

\section{MISSION SEQUENCE}

The Mariner 9 propulsion subsystem performed a midcourse correction five days after launch and three maneuvers at Mars-orbit insertion and two trims. Pyrotechnic valves shown in Fig. 2 provided positive isolation of propellants and pressurant for the five-month coast period between the first two maneuvers. The specific mission events and maneuver magnitudes are listed in $\mathrm{T}$ ablc 5.

The loss of the Mariner 8 spacecraft caused a change in maneuver strategy. The maximum allowable $\Delta V$ was committed to orbit insertion in order to achieve a 12 -hour orbital period and maximum rotation of the orbital line of apsides. Commitment of $40 \mathrm{~m} / \mathrm{s}$ was made for a single orbit trim to correct orbital period and time of periapsis passage. Periapsis altitude was allrwed to float in order to decrease spacecraft risk by reciucing the number of maneuvers.

A second midcourse maneuver was nut required because of the extreme accuracy of the first maneuver. Orbit insertion and the first trim went according to plan; the orbit insertion maneuver was so accurate that only one-third of the allocated $\Delta V$ was required to synchronize the orbit to the Goldstone Tracking Station with the first trim. The resulting excess $\Delta \mathrm{V}$ capability was used for a second trim to raise periapsis altitude from 1387 to $1650 \mathrm{~km}$ on December 30,1971. This increased periapsis altitude allowed greater picture overlap; the primary mapping mission could, therefore, be accomplished in a shorter period of time after the Mars dust storm had subsided. 
Another sequence change which did not affect total $\Delta V$ caF :ility, but rather the readiness of that capability, was a decision to leave the propellant line isolaijun valves open after orbit trim $l$. The gasline valve was closed to prc cect igainst regulator failure. The propellant lines we re left open Decause (.) there was no evidence of rocket engine valve leakage as determined by sbserved valve and injector temperatures and lack of trajectory or attitude disturbances, and (2) the line-open state would allow performance of any add:tional maneuvers required in a propellant-tank blowdown mode without co nmitting to a permanent line-open mode by opening valves 05 , F5. The visdom of that decision was borne out by the subsequent requirement for a second orbit trim maneuver.

\section{ANALYTICAL MODELING AND FLIGHT PERFORMANCE CORRELATIONS}

t. substantial effort was necessary to predict the in-flight performance of the subsystem. Accurate prediction was necessary, since up to $96 \%$ of the pro. ellant was expected to be consumed during the Mars orbit insertion maneuv"r, and one must be able to commit to later orbit trim maneuvers without endangering' se spacecraft as a result of propellant starvation of the rocket engine. Proper prediction of in-flight performance required the derelopmexit of modeling tools to predict and account for nit rogen saturation of the propellant during the six-month coast period and to predict and statistically analyze in-flight data.

\section{A. Nitrogell Solubi:" Effects and Mass Tränsport Model}

A portion $n$ : :se nitrogen pressurant gas used in the Mariner 9 propulsion subsyste " 1 dissolved into the propellants during the interplanetary cruise phase. The actual amount in solution was of interest because full saturation of the c-idizer at a tank pressure of $1.72 \times 10^{6} \mathrm{~N} / \mathrm{m}^{2}\left(250 \mathrm{lbf} / \mathrm{in}^{2}\right)$ would decrsase operating mixure ratio about $6 \%$ from the unsaturated operation poirt. Preflight testing with an oxidizer flow bench which simulated the propulsion s"lb ystem hydraulic circuit showed that (1) the engine injector is the onl ir component which exhibits significant resistance increase due to the twc-phase flow caused by gas coming out of solution, and (2) such a $r \geq s i s t a n c e$ incraase does not occur until the partial pressure of $\mathrm{N}_{2}$ in 
solution exceeds the injector inlet pressure, less vapor pressure. It was thus necessary to predict the nitrogen gas absorption level at orbit insertion so that the proper mixture ratio could be loaded.

A mathematical model of the Mariner 1971 propellant tanks was developed to predict (1) the rate of pressurant gas absorption into the liquid propellants, (2) the volume of gas bubble inside the Teflon bladders, and (3) the propellant tank pressures with an isolated gas supply. The model was F.ogrammed for use on the Univac 1108 computer to print and plot gas concentration, average gas concentration, bubble volume and tank pressure as functions of pressurant supply profile, radius, and time. Required inputs are propellant and initial bubble volumes, propellant diffusivity and solubility, bladder permeation coefficient, and the bladder thickness.

Nitrogen gas will permeate through the Teflon bladders and diffuse into the liquid propellants because of a concentration gradient that develops after propellant tank pressurization. These processes can be compared to the transfer of heat due to a temperature gradient. Thus an existing heat transfer program was used as a basis for the gas transport program.

In the gas diffusion model, the mass transport equations we re rewritten and solved as finite difference equations. The liquid propeliant volumes were as sumed spherical and contained within bladders exposed on the outside to pressurant gas. The liquid volume is divided into 10 concentric spheres and $r$ epresented as 10 liquid nodes (Fig. 7). The gas ullage volume outside the bladder and the bubble volume inside the bladde $r$ are represented by two gas nodes. Positions and volumes of each of the nodes and the conductance of each of the conductors are calculated by the program. The program recalculates each conductance as the bubble volume and surface area decrease.

Prefight predictions of saturation level at orbit irsertion were calculated using the spherical permeation/diffusion model just described. Predicted propellant tank pressures obtained from this analysis are plotted, along with flight data, in Fig. 8. IJote that a significant difference in curve shape and final pressure exists for the oxidizer tank, while only the rate of pressure decay is different for the fuel tank. 
Since certain as sumptions were necessary to accomplish the orbitinsertion saturation predictions, it was desirable to update the model to match the observed pressure decay curves. Pressure profiles which matched the flight data were obtained with the permeation/diffusion computer model by assuming different values for bladder area available, diffusion rate, and solubility. The revised constants were used to calculate $\mathrm{N}_{2}$ saturation pressures at orbit insertion of $1207 \times 10^{3} \mathrm{~N} / \mathrm{m}^{2}\left(175 \mathrm{lbf} / \mathrm{in}^{2}{ }^{2}\right)$ for the oxidizer and $1469 \times 10^{3} \mathrm{~N} / \mathrm{m}^{2}\left(213 \mathrm{lbf} / \mathrm{in} .^{2}\right)$ for the fuel. The oxidizer saturation level is very nearly equal to injector inlet pressure, so only a small amount of excess $\mathrm{N}_{2}$ would be expected to come out of solution. No mixture ratio shift which could be attributed to excessive saturation was observed during orbit insertion. The flight data tend to support the groundtest derived model of a saturation effects threshoid of injector inlet pressure but do not allow an evaluation of saturation effects per se because the threshold was not exceeded. The combination of ground and flight data, however, should be especially useful to future programs which use $\mathrm{N}_{2}$ as a pressurant gas.

\section{B. Operation and Performance Computer Program}

A digital computer program called PSOP (Propulsion Subsystem Operation and Performance) was developed to support Mariner 9 flight analysis. PSOP is a low-frequency simulation model of the complete propulsion subsystem. Figure 9 is a simplified block diagram of the program which shows information flow from an input data list through the program to output data. The program was used to predict flight telemetry data, generate thrust and spacecraft-mass time functions for flight maneuver analyses, perform malfunction analyses, and investigate effects of variations in system initial conditions.

On a given run, PSOP will simulate preburn, burn, and postburn behavior. A typical preburn event is tank pressuri 2 ation by opening a pyrotechnic valve. Postburn activity includes regulator lockup and heat transfer between fluids and tanks. A burn simulation will continue until one of two conditions a re met. Spacecraft velocity change can be input and total burn time will be determined or burn time can be specified to determine the spacec raft velocity inc rement. 
The propulsion model was formulated by first describing the significant physical processes in each of the propulsion components and then organizing these desciptions into a large equation set. Like the physical hardware, component identity is retained and interactions between components (equations) are required to achieve a system solution. Figure 10 is a simplified block diagram of the propulsion model.

The propulsion performance portion of PSOP keeps track of the varying mass elements of the spacecraft, that is, the instantaneous mass of oxidizer, fuel, and gaseous nitrogen in the various containers. This information is coupled with the fixed spacecraft mass in an 8-element mass model to determine total mass and spacecraft center-of-mass location.

Since the spacecraft autopilot forces the thrust vector to point through the spacecraft center of mass, the thrust pointing angle can be determined from the location of the center of mass and the engine gimbal center. The gimbal actuator positions are computed from the thrust pointing angle and the results converted to telemetry output data number. Since the spacecraft center-of-mass movement during a burn is a measure of the integrated engine mixture ratio, and the gimbal actuator arm lengths indicate the direction of the spacecraft center of mass, average engine mixture ratio can be inferred from the gimbal actuator positions.

\section{Flight Analysis Computer Frogram}

The PSOP program provided flight performance predictions, but a tool vas also required to analyze the flight data and compare the data with predi,tions. A Propulsion Statistical Analysis Program (PSAP) was developed per the formulation of Alford (Ref. 1) to perform this function. This program uses the statistical residual technique used by trajectory ana rsts and was readily available in computer subroutine libraries. Reference 2 treats the adaptation for this application.

Some applications of the residual technique use time as a running variable and calculate a solution at every $n$ seconds. One of the primary inputs for the problem at hand was total velocity change; this was not observable as a function of time from on-board sources, so a decision was made to keep the program simple and perform an average analysis for the entire burn. 


\section{Performance Results}

Of the four propulsion maneuvers performed, only the orbit insertion maneuver was long enough to provide sufficient data for a thorough comparison with preflight predictions. PSOP was used with empirical input data obtained from the Marine $\mathbf{r} 9$ and similar propulsion subsystems to calculate predictions. A weighted-least-squares fit of the flight data and predictions (using PSAP) resulted in the best-fit data list of Table 6. Also listed is the estimated $1-\sigma$ uncertainty of each parameter in the best-fit column. Burn time, chamber pressure, and engine mixture ratio are all within $0.5 \%$ of preburn predictions. The flight data were not sufficiently accurate as compared with engine acceptance tests to improve knowledge of specific impulse, so little change was noted there. The increase in mixture ratio and burn time compared with the corrected predictions was attributed to a $0.8 \%$ increase in fuel resistance. Note, however, that the fuel resistance change required to provide a data match is less than the $1-\sigma$ uncertainty of that parameter.

The revised propulsion model was used to calculate a set of best-fit performance predictions. An example of this, engine chamber pressure, is plotted in Fig. 11 with preburn and best-fit PSOP output curves. One may note that the telemetry resolution available with the pressure measurements would have made detailed performance analysis difficult without the statistical program PSAP.

A performance summary for the four propulsion maneuvers is presented in Table 7. New performance calculations were performed after orbit insertion for the actual flight sequence. Burn-time predictions are listed for all burns in Table 7 with the original and revised propulsion models. The excellent agreement between flight data and predictions provides a validation of the prediction tools used.

\section{CONCLUSIONS}

For the Mariner 9 orbiter mission, it was necessary to develop a large, bipropellant propulsion system to replace the small monopropellant system used on early Venus and Mars flyby Mariners. Cost effectiveness 
was achieved by the use of design simplicity rather than redundancy. Characterization of the subsystem through ground testing on a component, subassembly, and subsystem level provided confidence in the design and performance capability. Application of the propulsion module approach, coupled with the use of "pathfinders" for all critical operations proved as successful on this larger sized subsystem as it had on previous Mariners.

In order to properly load the subsystern and commit subsequently to each propulsion maneuver, modeling tools were developed to predict in-flight performance. These tools led to a $0.5 \%$ agreement between observed performance and preflight predictions. These techuologies are presently being applied to the Viking Orbiter 1975 spacecraft propulsion system.

\section{REFERENCES}

1. Alford, M. W., Jr., Mathematical Aspects of Flight Analysis Computer Programs, AIAA Paper 68-583, presented at the AIAA 4th Propulsion Joint Specialists Conference, Cleveland, Ohio, Juse 10-14, 1968, American Institute of Aeronautics and Astronautics, New York, N. Y.

2. Cork, M. J., French, R. L., Leising, C. J., and Schmidt, I, D., From Earth to Mars Orbit - Mariner 9 Propulsion Flight Performance with Analytical Correlations, to be presented at the 8th Propulsion Joint Specialists Conference, New Orleans, La., November 29 December 1, 1972, American Institute of Aeronautics and Astronautics, New York, N. Y. 
Table 1. Propulsion subsystem performance characteristics

\begin{tabular}{|c|c|c|}
\hline Parameter & & \\
\hline Vacuum thrust & $1334 \pm 89 \mathrm{~N}$ & $(300 \pm 20 \mathrm{lbf})$ \\
\hline Vacuum specific impulse & $2775 \pm 49 \mathrm{~N}-\mathrm{s} / \mathrm{kg}$ & $(283 \pm 5 \mathrm{lbf} s / 1 \mathrm{bm})$ \\
\hline $\begin{array}{l}\text { Thrust chamber } \\
\text { expansion ratio }\end{array}$ & & $40: 1$ \\
\hline $\begin{array}{l}\text { Thrust chamber } \\
\text { pressure }\end{array}$ & $\begin{array}{l}806.7 \pm 55 \\
\left(\times 10^{3}\right) \mathrm{N} / \mathrm{m}^{2}\end{array}$ & $\left(117 \pm 8 \mathrm{lbf} / \mathrm{in}^{2}\right)^{2}$ \\
\hline $\begin{array}{l}\text { Propellant loaded mix- } \\
\text { ture ratio, } O / F \text { by } \\
\text { weight }{ }^{2}\end{array}$ & & $1.50 \begin{array}{l}+0.05 \\
-0.03\end{array}$ \\
\hline $\begin{array}{l}\text { Nominal oxidizer } \\
\text { flow rate }\end{array}$ & $0.289 \mathrm{~kg} / \mathrm{s}$ & $(0.637 \mathrm{lbm} / \mathrm{s})$ \\
\hline Nominal fuel flow rate & $0.192 \mathrm{~kg} / \mathrm{s}$ & $(0.424 \mathrm{lbm} / \mathrm{s})$ \\
\hline $\begin{array}{l}\text { Propellant load } \\
\text { capacity }\end{array}$ & $462.7 \mathrm{~kg}$ & $(1020 \mathrm{lbm})$ \\
\hline $\begin{array}{l}\text { Usable propellant load } \\
\text { capacity }\end{array}$ & $440 \mathrm{~kg}$ & $(970 \mathrm{lbm})$ \\
\hline $\begin{array}{l}\text { Propellant loading } \\
\text { accuracy }\end{array}$ & $\pm 0.45 \mathrm{~kg}$ & $( \pm 1.0 \mathrm{lbm})$ \\
\hline Minimum burn duration & & $0.4 \mathrm{~s}$ \\
\hline $\begin{array}{l}\text { Shutdown impulse } \\
\text { variation, } 3 \sigma\end{array}$ & $\pm 22.2 \mathrm{~N}-\mathrm{s}$ & $( \pm 5 \mathrm{lbf}-3)$ \\
\hline
\end{tabular}


Table 2. Mariner Mars 1971 propulsion weight summary (dry mass)

\begin{tabular}{lcc}
\hline \multicolumn{1}{c}{ Description } & \multicolumn{2}{c}{ Dry mass } \\
\hline & $\mathrm{kg}$ & $\mathrm{lb}$ \\
\hline Pressurant tank assembly & 24.9 & 55.0 \\
Pressurant control as sembly & 5.6 & 12.4 \\
Pressurant check-relief assembly (2) & 2.1 & 4.6 \\
Propellant tank assembly (2) & 30.4 & 67.0 \\
Propellant isolation assembly (2) & 10.2 & 22.4 \\
Rocket engine assembly & 7.8 & 17.1 \\
Tubing and fittings & 5.9 & 13.1 \\
Thrust plate assembly & 5.7 & 12.6 \\
Truss and ring assembly & 9.1 & 20.1 \\
Propellant tank thermal covers (2) & 2.5 & 5.5 \\
Cable harnesses (2) & 2.2 & 4.9 \\
Gimbal actuators (2) & 2.5 & 5.6 \\
Squibs (15) & 1.0 & 2.3 \\
\hline Total propulsion subsystem & 110.0 & 242.6 \\
\hline
\end{tabular}


Table 3. Type approval test series 1

\begin{tabular}{|c|c|}
\hline Test event & Simulated flight event \\
\hline Propellant vibration ( 3 axes) & Launch \\
\hline Installation in vacuum chamber & 2 -week coast \\
\hline Moog valve open & Moog valve open \\
\hline Pl, Ol, Fl open & $\mathrm{Pl}_{1} \mathrm{Ol}, \mathrm{Fl}$ open \\
\hline $8-s$ burn & Midcourse burn \\
\hline l-day coast & 1 -week coast \\
\hline P2 close & P2 close \\
\hline $\mathrm{O} 2, \mathrm{~F} 2$ close & O2, F2 close \\
\hline Check valve test & - \\
\hline 1-day coast & 6 -month coast \\
\hline O3, F 3 open & O3, F3 open \\
\hline P3 open & P3 open \\
\hline 10-s burn & Midcourse burn \\
\hline l-day coast & 3-week coast \\
\hline $900-s$ burn & Orbit insertion burn \\
\hline 2-day coast & 2 - to 4-day coast \\
\hline $0.4-s$ burn & Orbit trim burn \\
\hline 3-day coast & 2 - to 4-day coast \\
\hline $40-s$ burn & Orbit trim burn \\
\hline- & Coast \\
\hline- & Close P4, O4, F4 \\
\hline- & Orbit planet \\
\hline
\end{tabular}


Table 4. Type approval test series 2

\begin{tabular}{cl}
\hline Test event & Simulated flight event \\
\hline 900 -s burn & Orbit insertion burn \\
3-day coast & 2- to 4-day coast \\
16-s burn & Orbit trim burn \\
1-day coast & 2- to 4-day coast \\
- & Orbit trin bui $n$ \\
- & Coast \\
P4, O4, F 4, close & Close P4, O4, F4 \\
1 -day coast & Orbit planet \\
O5, F5 open & - \\
P5 open & - \\
$10-8$ burn & - \\
1 -day coast & - \\
\hline
\end{tabular}


Table 5. Propulsion event sequence

1. Launch with propellant tanks at low pressure

2. Vent air from liquid lines

3. Pyro valves open (Pl, Ol, Fl) to pressurize tanks and lines

4. Midcourse 1 firing (5.1 s)

6.7

May 30

5. Pyro valve cl - $d(P 2)$ to isolate gas supply from propellant tanks

6. Pyro valves closed (O2, F2) to isulate propellants from engine

7. Pyro valves open (P3, O3, F3) to repressurize system

8. Orbit insertion firing (915 s)

1600.5

Nov 13

9. Orbit trim 1 firing $(6.4 \mathrm{~s})$

15.3

Nov 15

10. Pyro valve closed (P4) to isolate gas supply from propellant tanks

11. Orbit trim 2 firing $(17.3 \mathrm{~s})$ in blowdown mode

41.8

Dec 30 


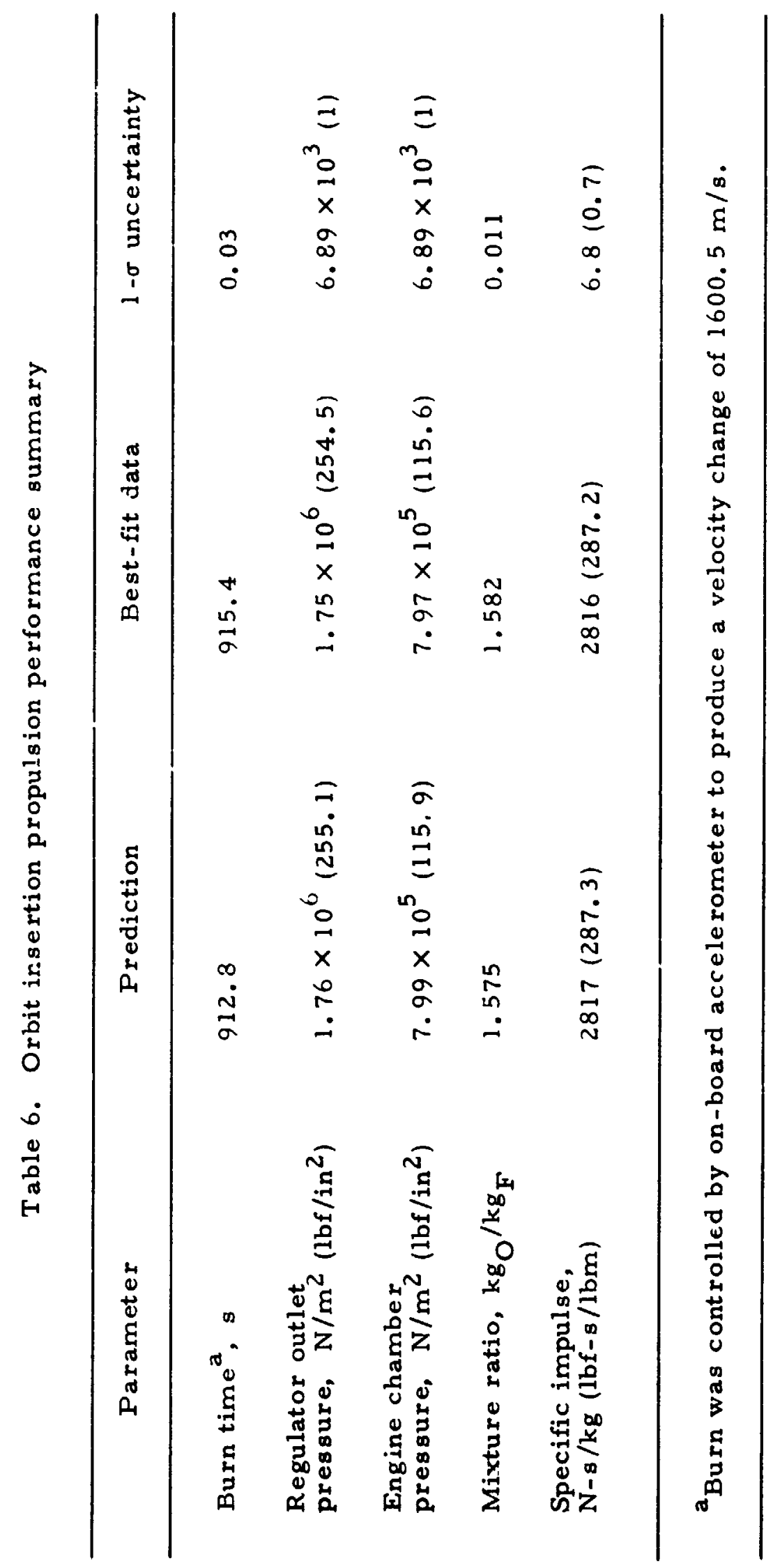




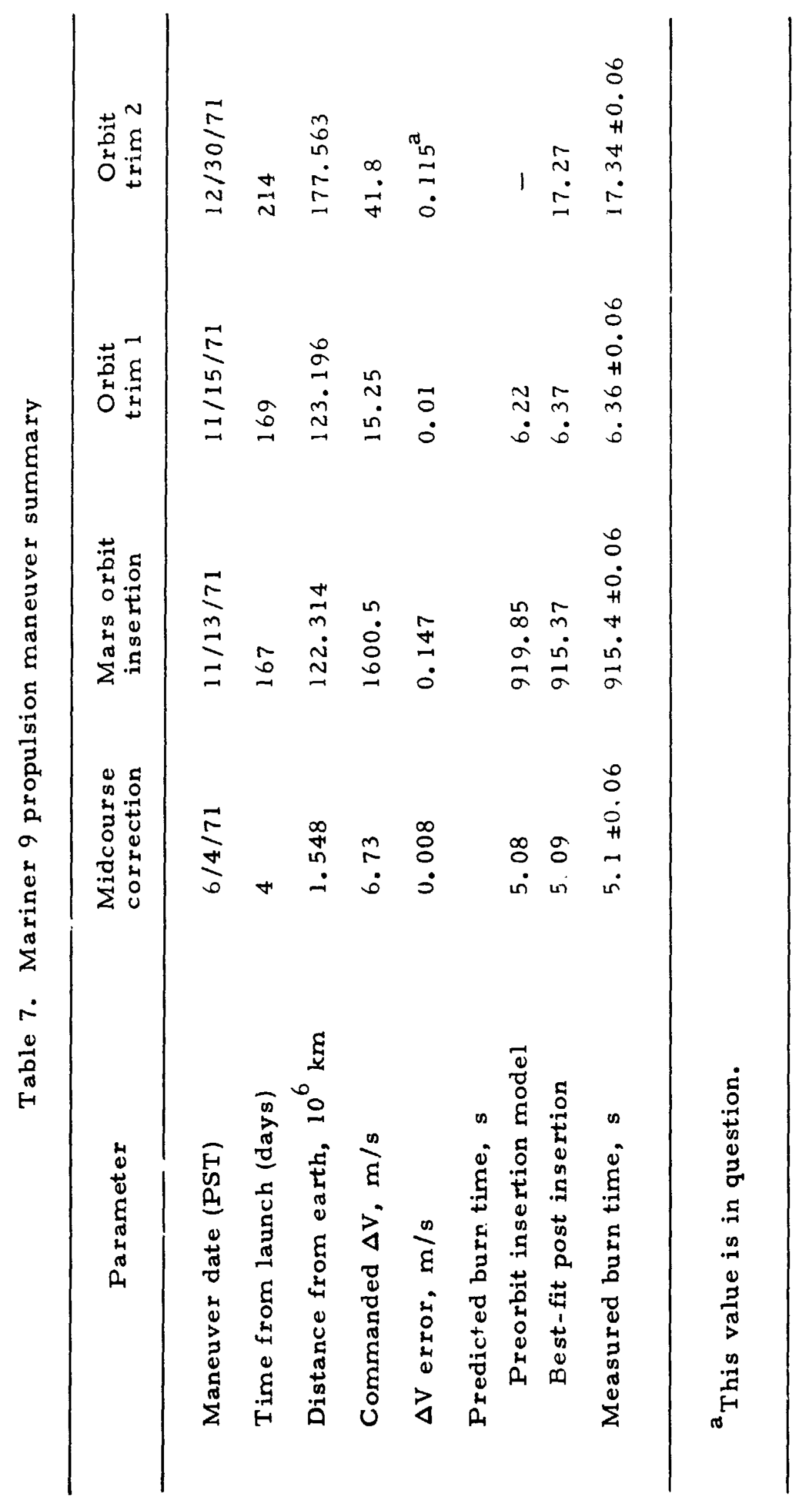




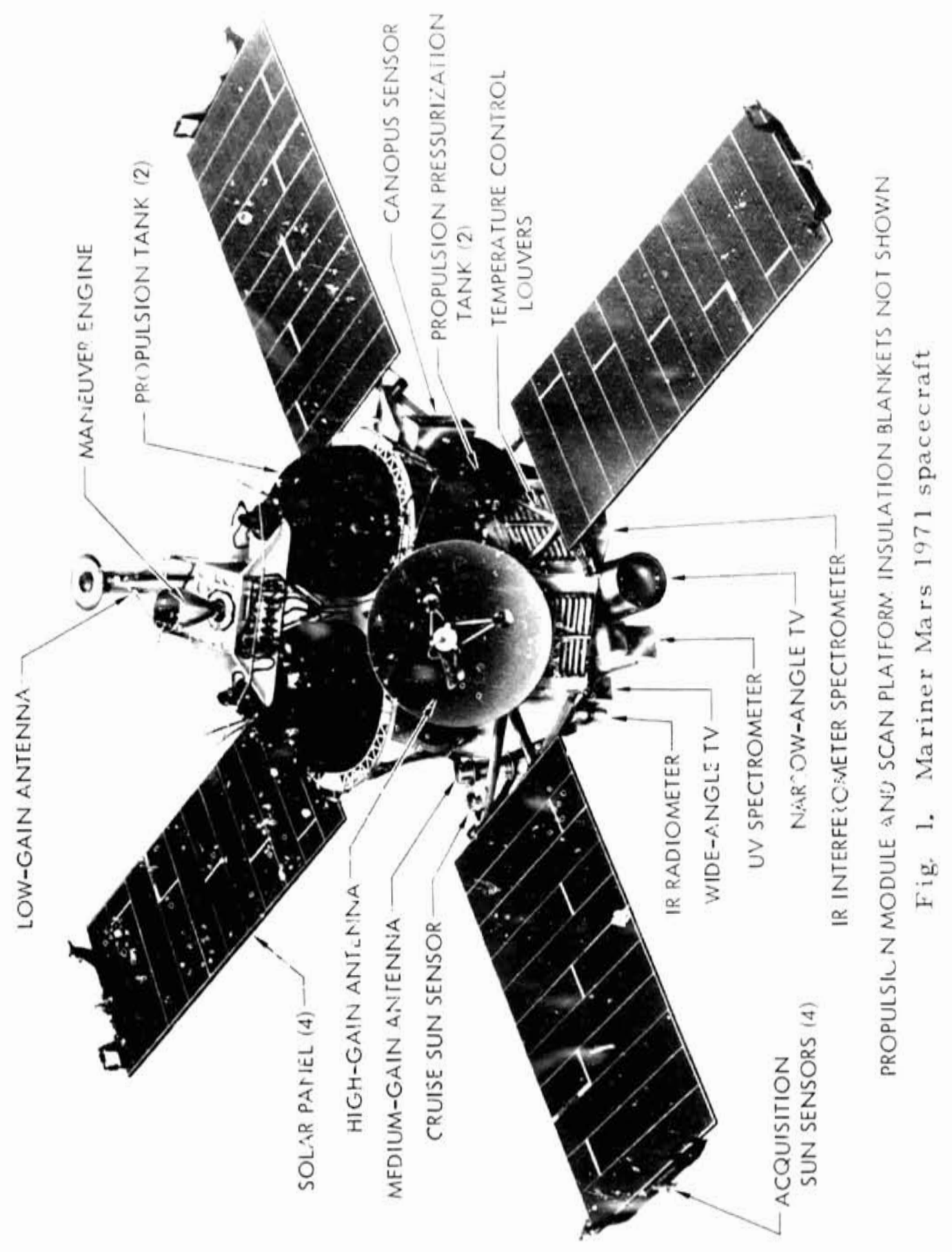




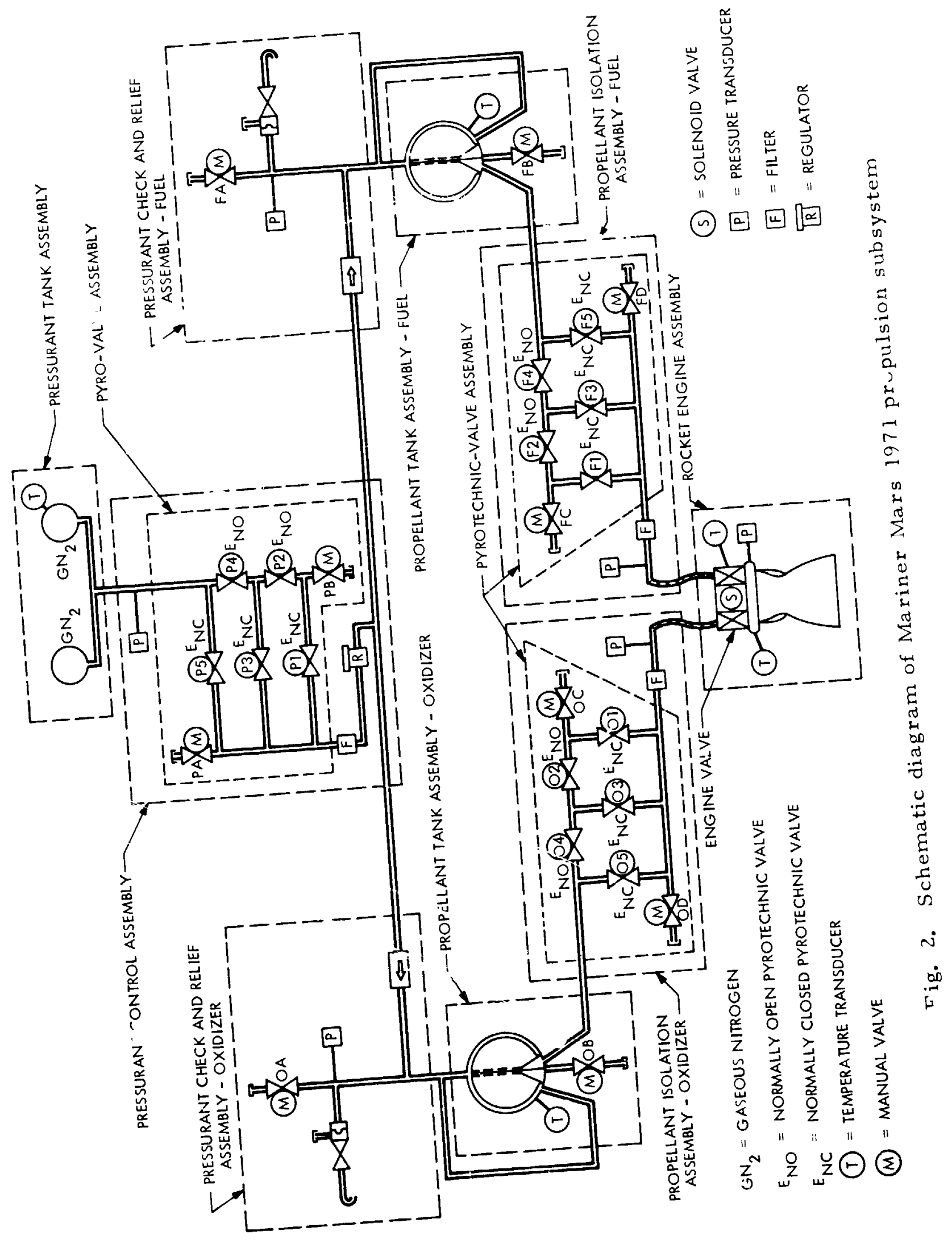

JPI. Technical Memorandurs 33-574 


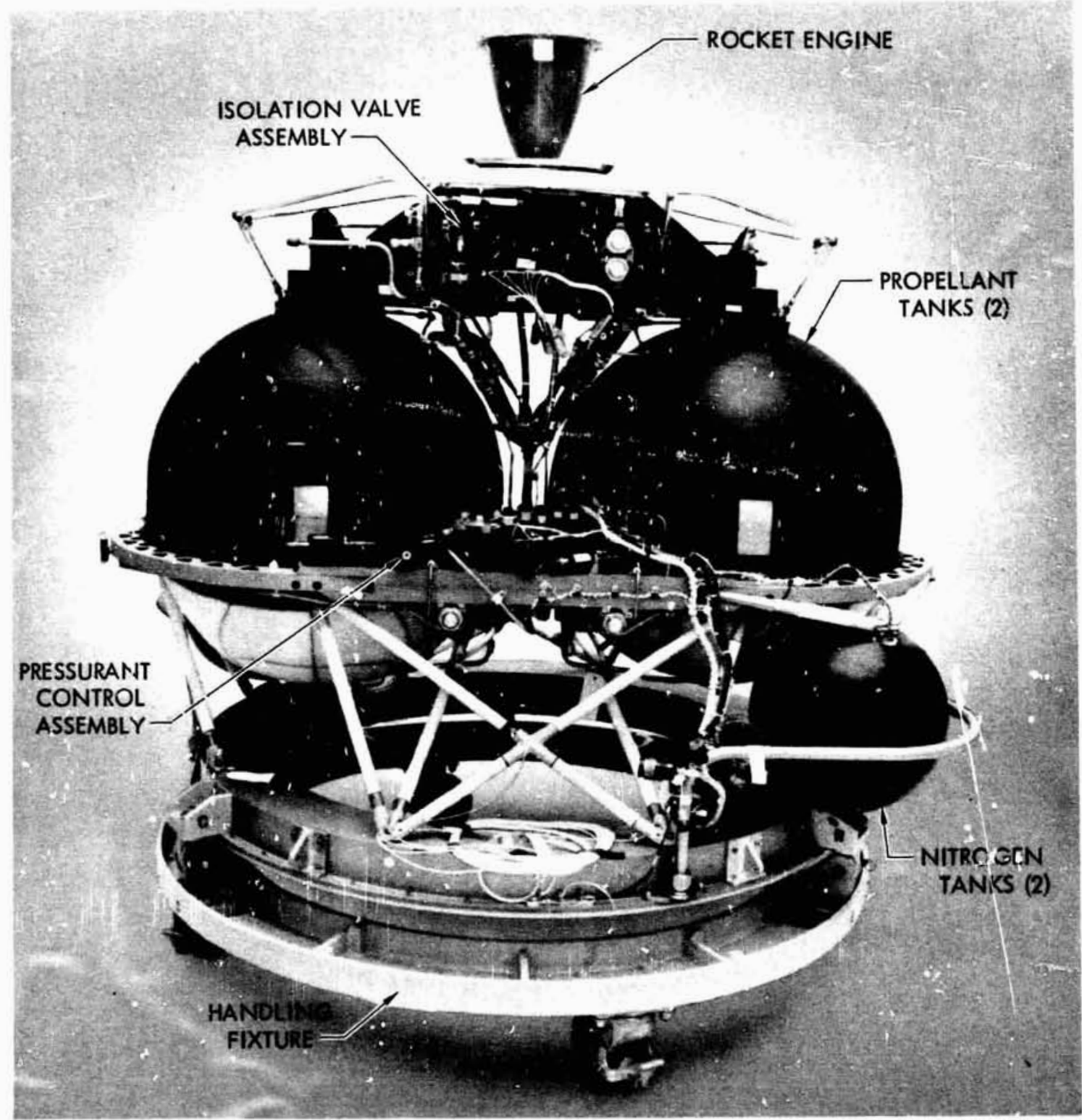

Fig. 3. Mariner 9 propulsion subsystem 


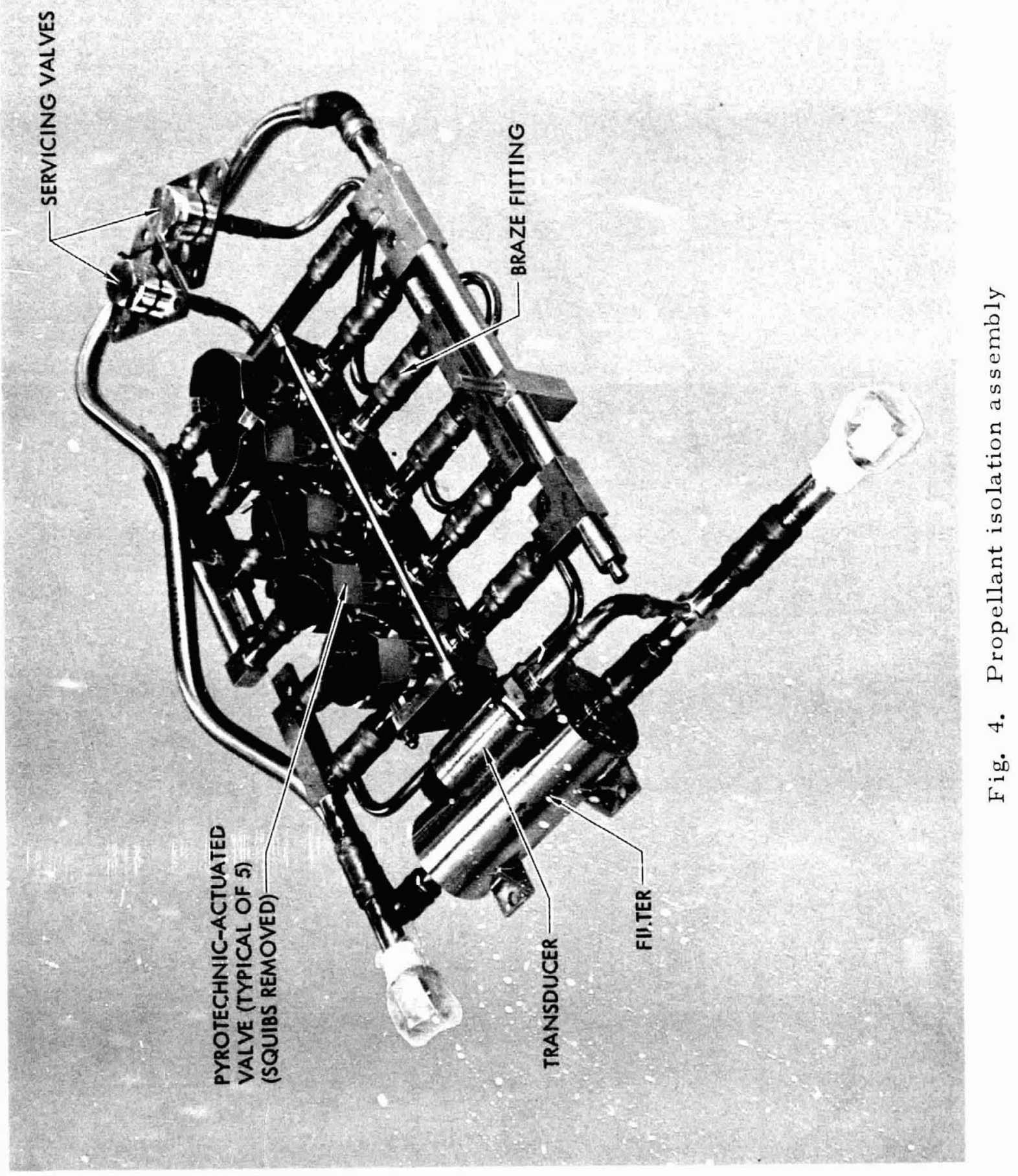

JPL Technical Memorandum 33-574 


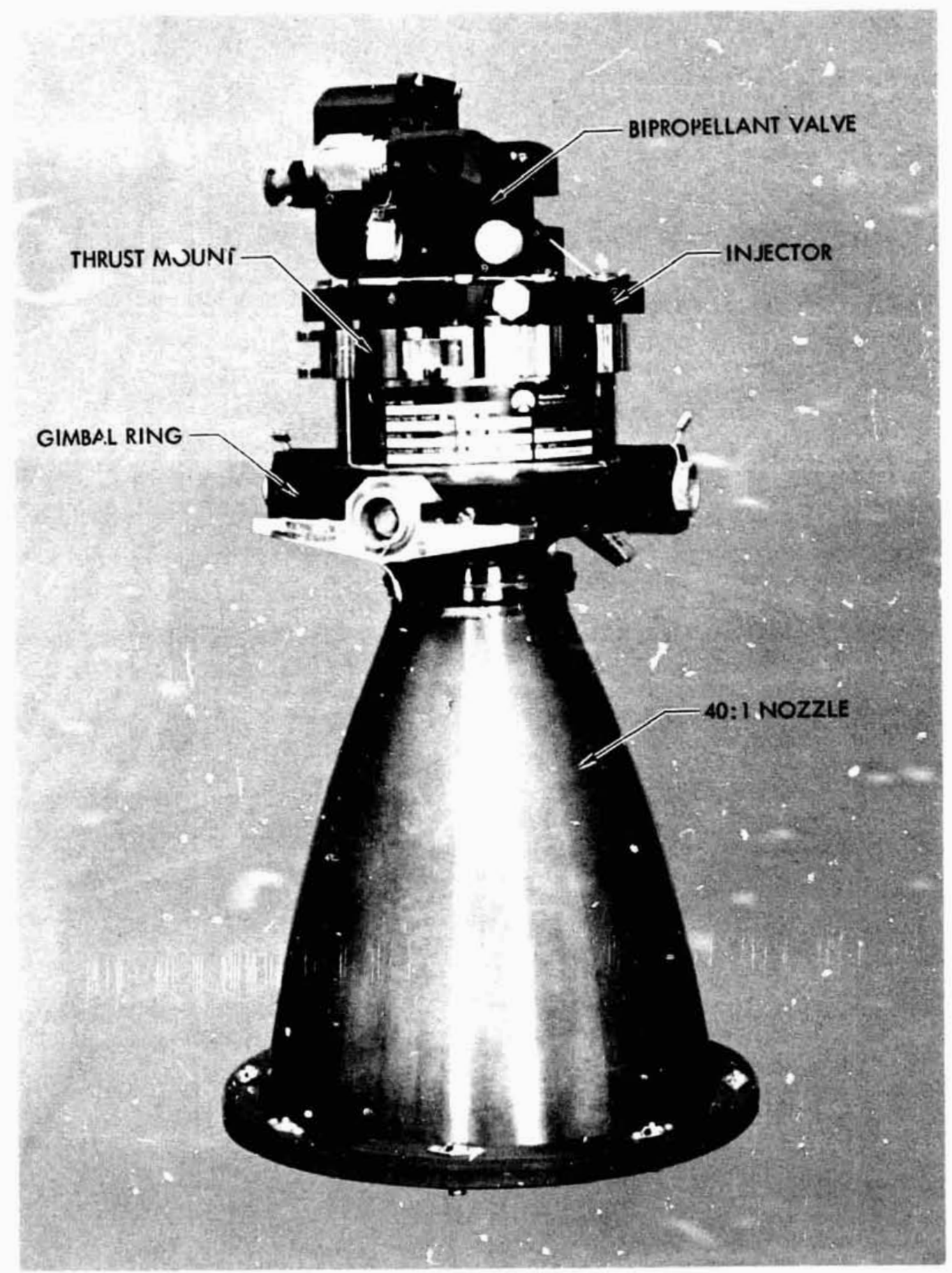

Fig. 5. Mariner Mars 1971 rocket engine assembly 


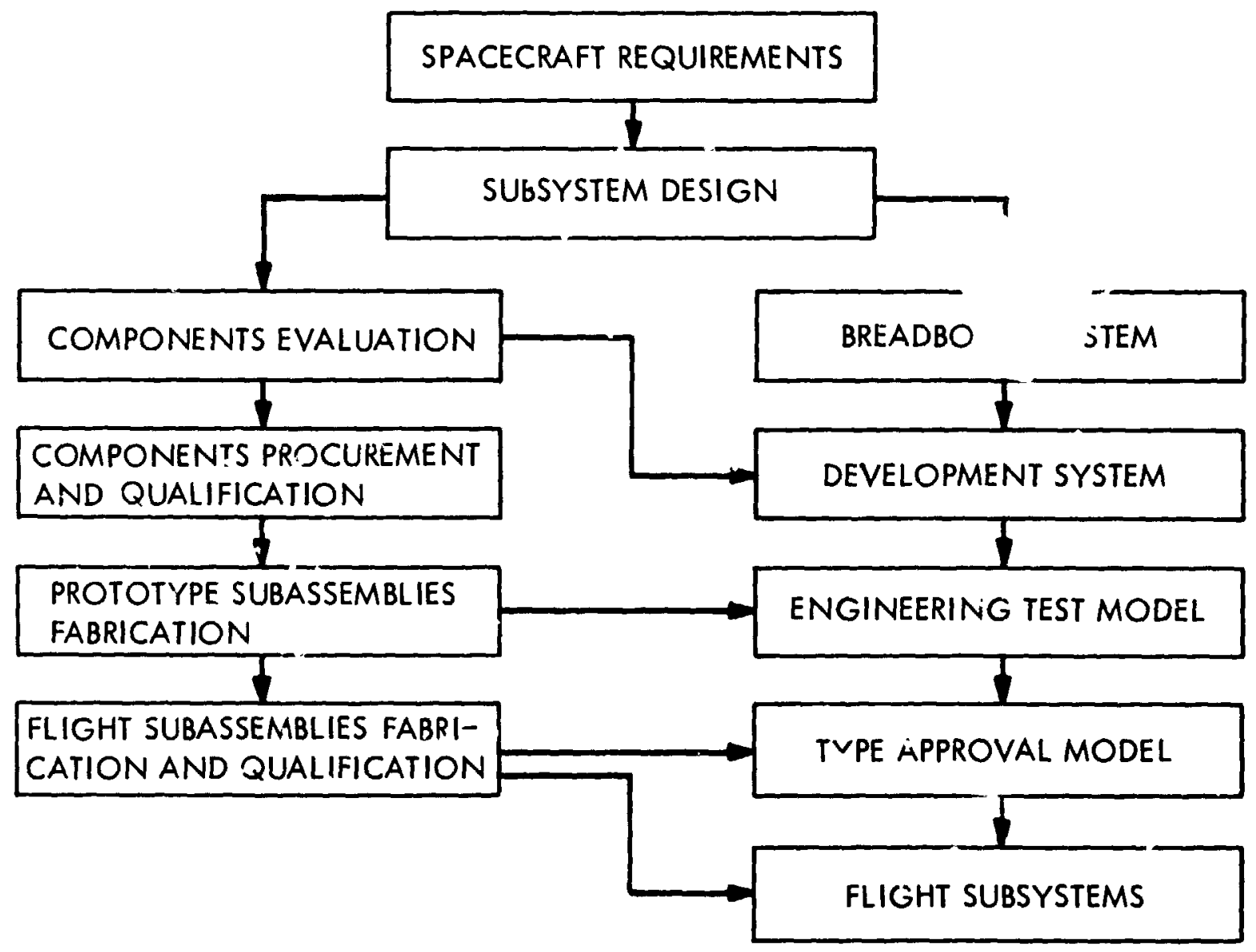

Fig. 6. Development sequence 


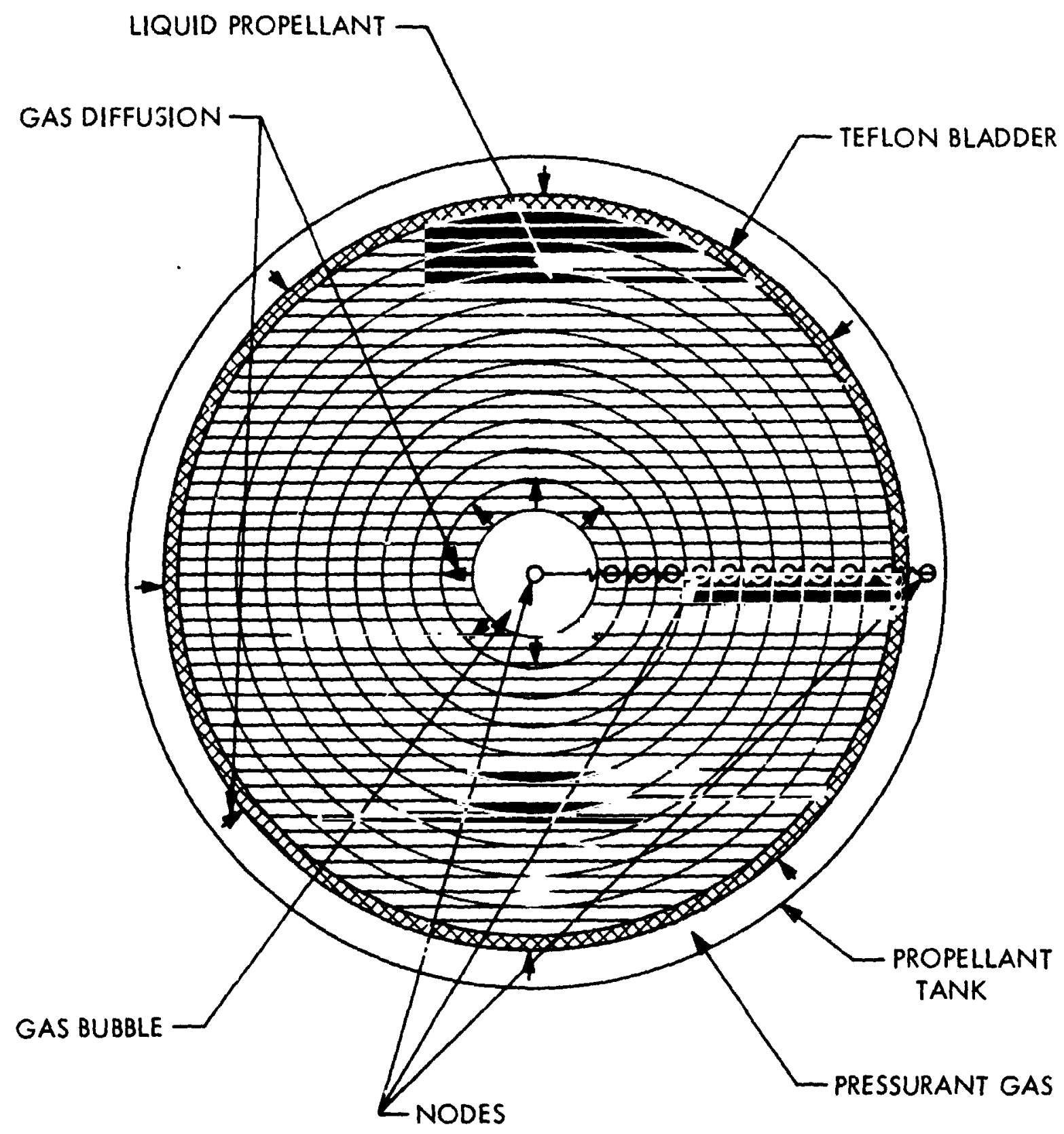

Fig. 7. Propellant tank gas diffusion model 


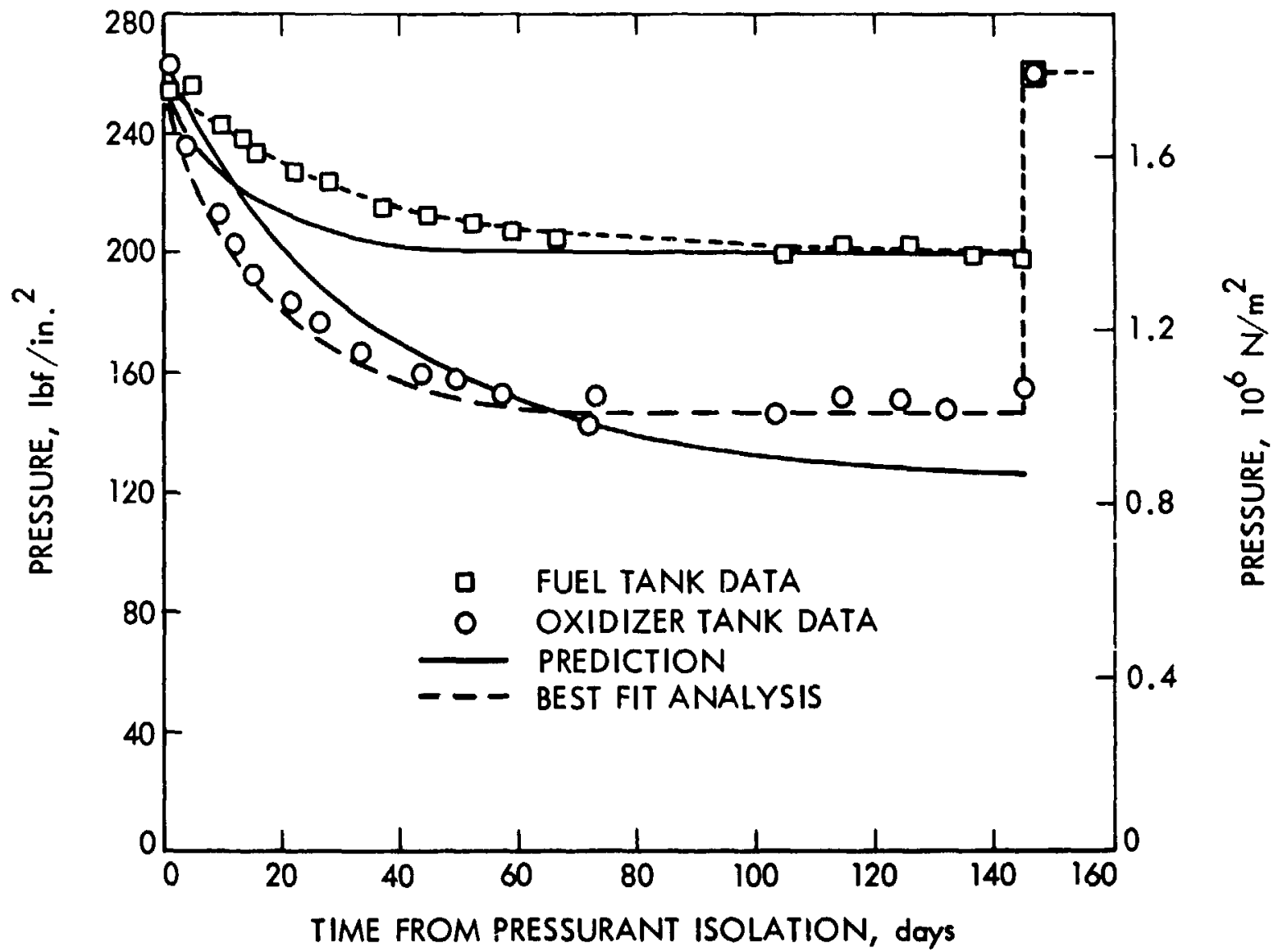

Fig. 8. Propellant tank pressures compared with saturation model predictions 
INPUT

PSOP

OUTPUT

AS A FUNCTION OF TIME

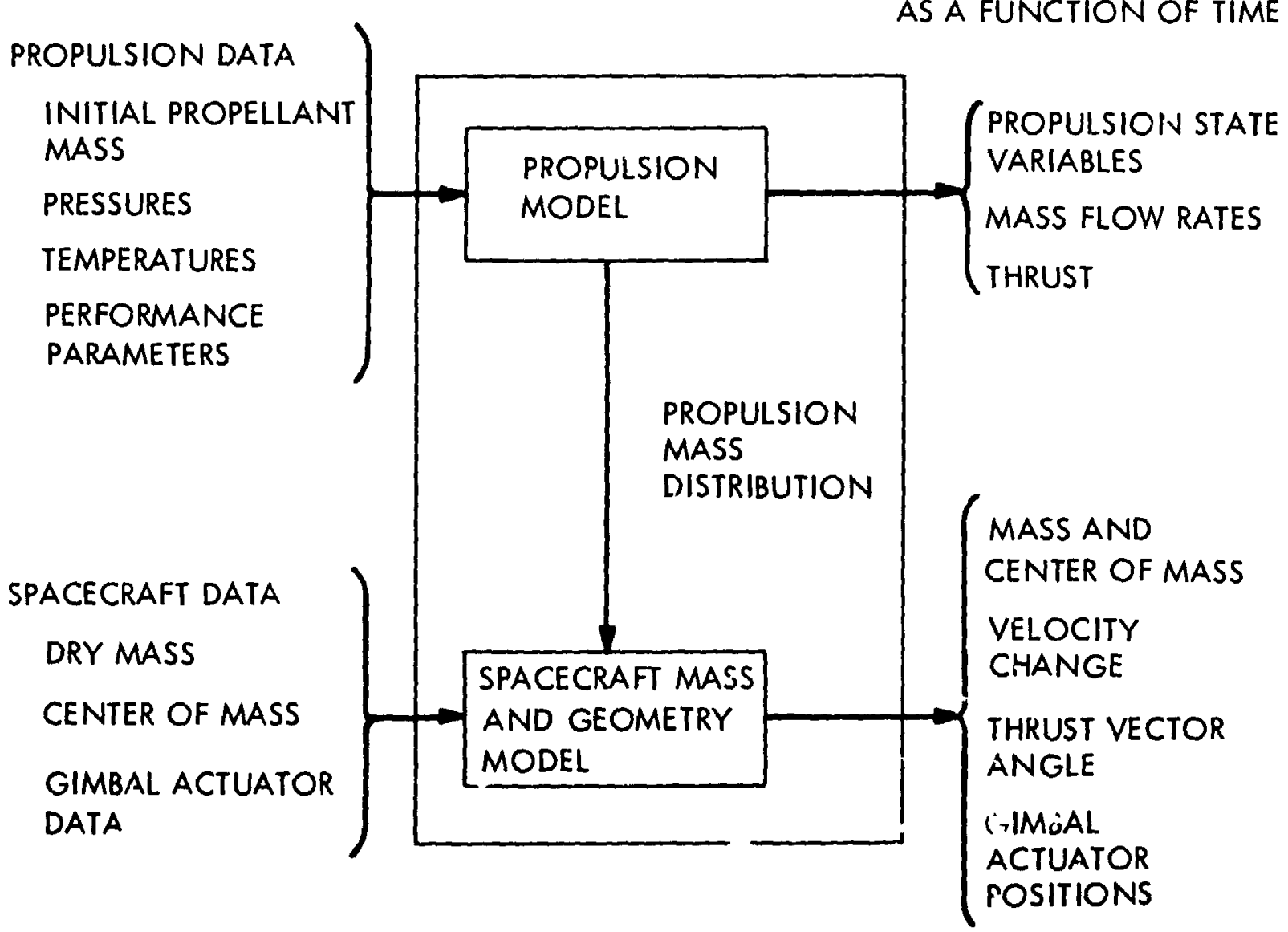

Fig. 9. Subsystem performance prediction program 


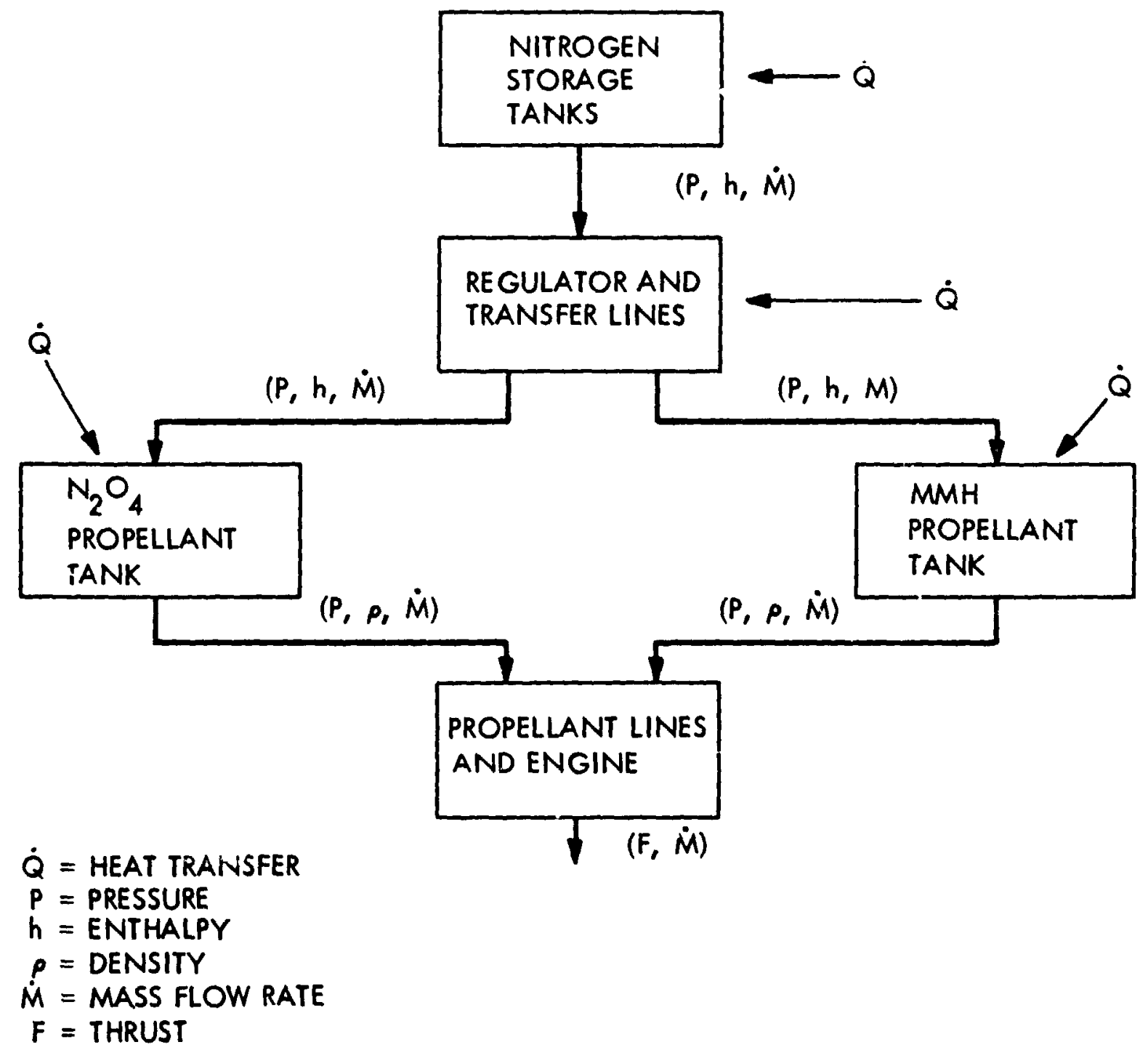

Fig. 10. Propulsion model of PSOP block diagram 


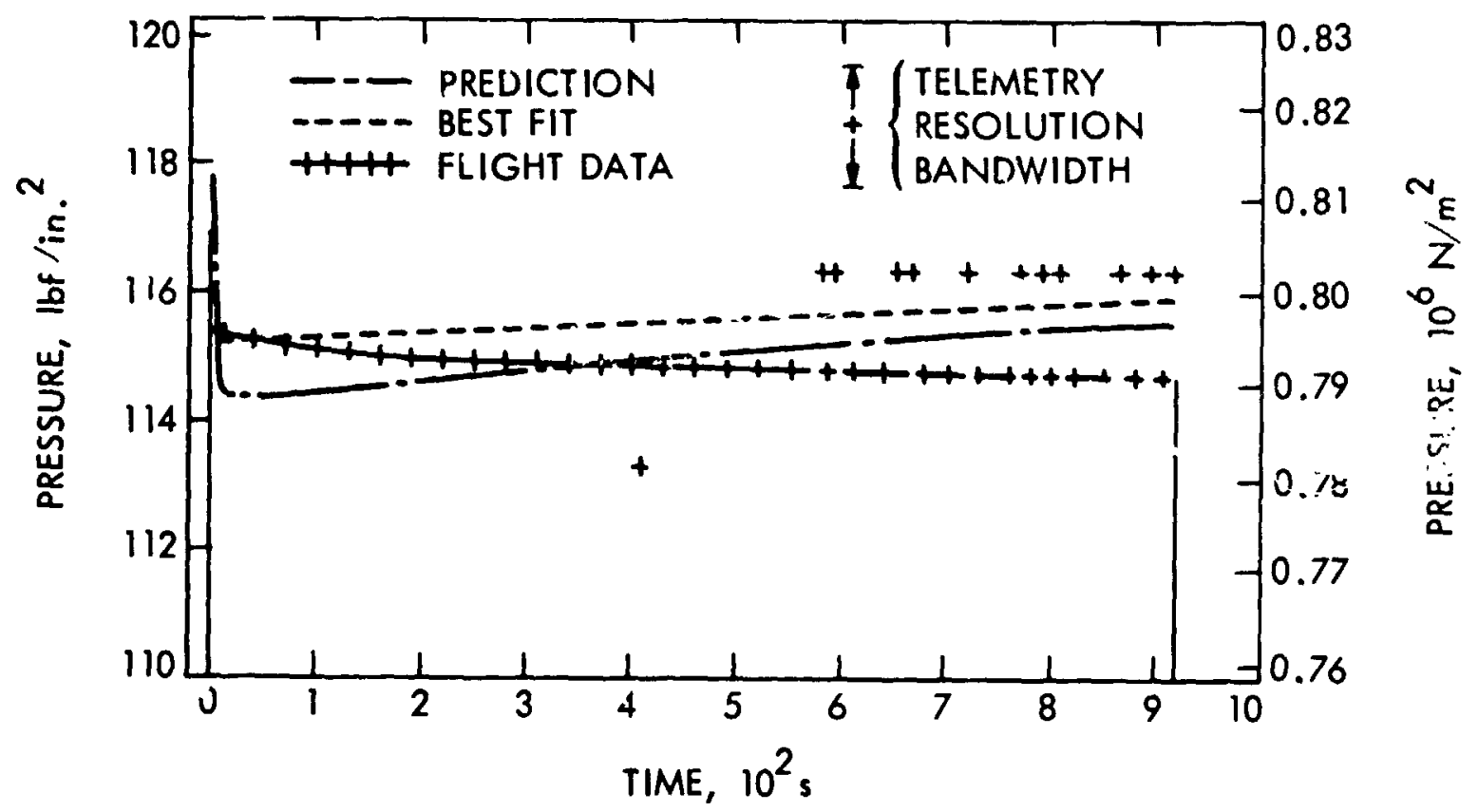

Fig. 11. Thrust chamber pressure during orbit insertion 
TECHNICAL REPORT STANDARD TITLE PAGE

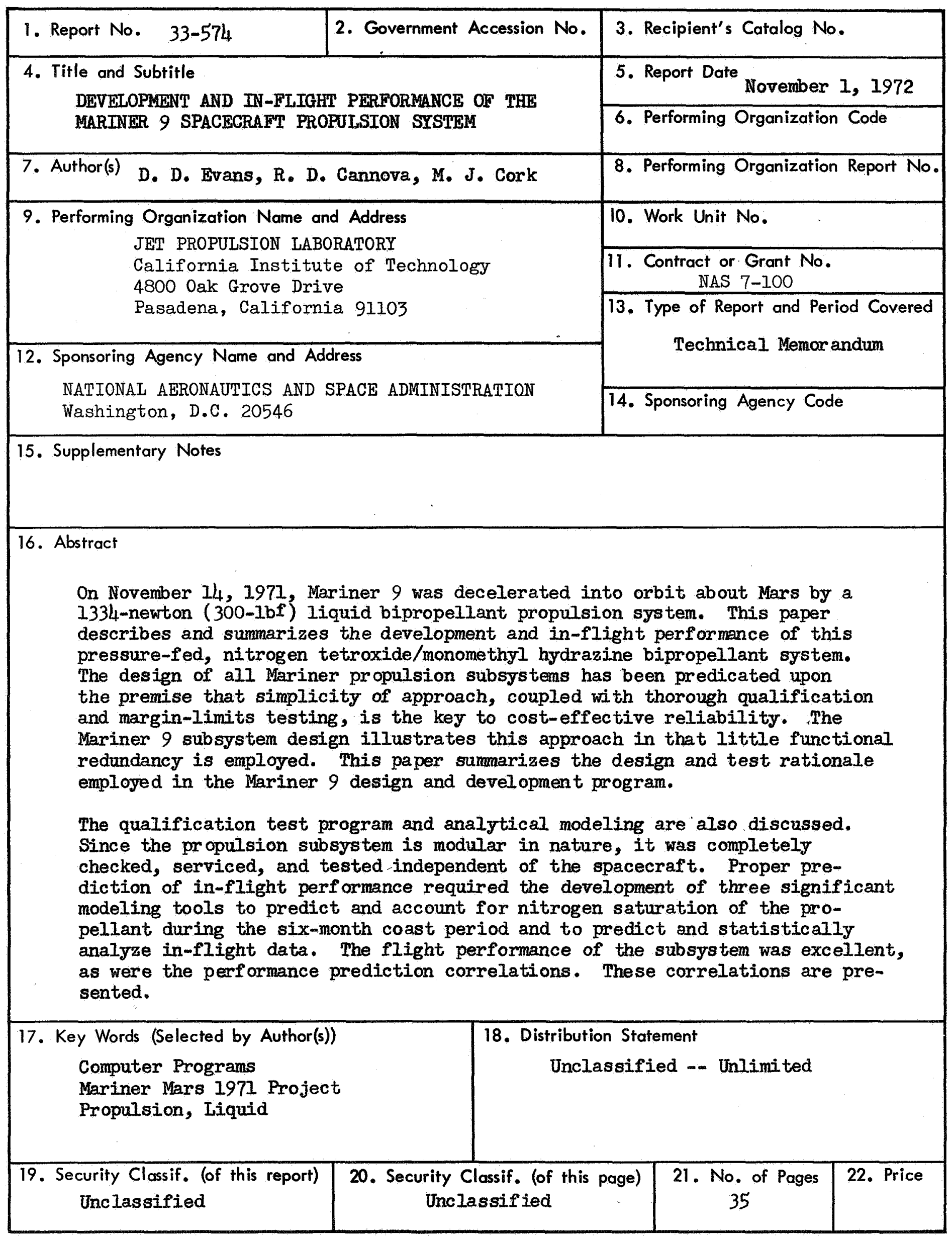

